\title{
ETHNO-PSYCHOLOGICAL ASPECTS OF MODERN EDUCATION
}

\author{
Asiya Kukubaeva \\ Kokshe Academy, Kazakhstan
}

\section{ABSTRACT}

This article presents the role and influence of social factors on the development of education in Kazakhstan. Transformation of consciousness of the people led to the modification, but not to the loss of basic, traditional values of the Kazakh people. The educational system defines a level of formation of youth outlooks. The last is that psychological environment within the limits of there is an acquisition of knowledge. On the basis of interests, valuable orientations processes of training, education and development of a personality are carried out. Thus, the outlook allows to integrate knowledge, defines a vital position and spiritual shape of people. In other words, formation, and outlook are interconnected among themselves that speaks about an urgency of formation of outlook in teaching and educational process. One of the basic directions of formation is education of Kazakh patriotism, formation of national consciousness. In Kazakhstan purposeful work on formation of positive tolerant relations is necessary.

\section{JEL CLASSIFICATION \& KEYWORDS}

I21 Development of Education - Education System Processes of Training - Teaching and Educational Process National Consciousness.

\section{INTRODUCTION}

Global changes occurring around the world, socio-political reality in the country are making great demands on the educational process. As rightly noted by the President of Kazakhstan N. Nazarbayev, today we task to create the knowledge-based society, to train the intellectual elite of the country. Without educated people, without a developed science, our republic will have no prospects [1, p. 2].

Gaining the independence and sovereignty Kazakhstan me several new problems, understanding of which was, first, hampered by the absence of experience of independent existence as a government, secondly, it demanded to decide its decision for the short time. The development of the republic in terms of market relations refers to these vital processes of modernity.

In higher education there has been a number of trends that reflect the peculiarities of its formation at the present stage. Firstly, formed non-governmental sector in the higher education system.

Secondly, the educational services market increased competition, which began to grow, even within the private universities. This trend contributes to a certain extent improve the quality of education. Another feature of modern education is the emergence of new specialties that have arisen on the basis of interdisciplinary studies. They also help to improve the education system the country, introducing new subjects, development of innovative technologies.

Progressive development of mankind has at its core the integration of the economy, referred to as globalization. This process of renewal of the social system, which involves dramatic changes in social structure, as well as in human psychology. Towards this may be obstacles, but this process is unstoppable. In general, globalization - a positive factor contributing to the progress of Government to preserve and share their culture.

Globalization has not only progressive but also accompanied by the collapse of the former system of values. It led to the emergence of psychological shock, which is manifested in the development of adverse events. It turned out that people were not psychologically prepared for sudden changes in their lives.

We are witnessing the manifestation of such phenomena a: radicalism, anti-immigrant mood of a certain part of the youth, the growing influence of extremist groups, the activity of fascist politicians. The result of the impact of globalization is the international terrorism. For many states the fight against it has become nationwide problem.

The problem of globalization is relevant for Kazakhstan, which brought together the representatives of different nations. A.N. Nysanbayev offers multiculturalism as a model of functioning and development of Kazakhstan society. It involves the interaction, "Development of multifaceted," which includes identity and ethnicity [2, p. 27].

In order to remain viable in the new economic situation, the values of traditional culture should be to some extent modernized. However, the current is to address the roots of the spiritual sphere of the Kazakh people - to its traditional ethics, philosophical views of educators Kazakh, Kazakh Soviet school of philosophy, ideas which can objectively and deeply understand the realities of modern life.

There are different views on this new stage of the Kazakh development. So, K. Mardanov [3, p. 102] stands for the fact that the idea of transition to the market seized the whole of society and became a national one. But it is important, in my opinion, take into account the peculiarities of the Kazakh mentality. It is necessary to explain for the people the peculiarities of the phased transition to the market. Upcoming changes in the economic life of the country will create conditions for the revival of national culture, will stand on a par with the world's leading communities.

With the development of market relations Kazakhs very difficult to accept the formula of individualism in the form in which the latter is cultivated in western culture. Well-known Kazakh poet and activist for human rights AM Shakhanov notes that market relationships break down age-old moral values and moral principles of the Kazakh people, has a deleterious effect on people's minds. He proposes to unite to preserve the unique culture of its people.

Through the national consciousness and on its basis formed elements of universal consciousness. Ethno-cultural specificity of thinking, human behavior is revealed in the mentality of the people, and is comparable with globalization.

Accounting for specific ethnic group, his mentality leads us to believe that it is necessary to develop a national culture, in particular, Kazakh. Awareness of national values will allow the country to adapt to the rigors of globalization. Many researchers have turned to such pressing matters as family

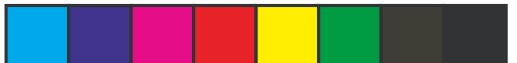




\section{ETHNO-PSYCHOLOGICAL ASPECTS OF MODERN EDUCATION}

relations, which form the personality, but at the same time themselves are determined by ethnic and cultural features.

So, in a traditional Kazakh family clearly defined relationship of the spouses, fathers and children. According to standards management controls husband, and household goods and food products is responsible for his wife. Therefore the burden of social labor always lay on the shoulders of men. Knowingly Kazakhs say "Man - the head, the woman - his neck." Moreover, the head of the family - a role model, he educator and mentor children. As a rule, it instills in children the skills that require stress, volitional effort, dedication, brings a sense of duty and responsibility. $\mathrm{He}$ is, to a greater extent, initiates their offspring to public concerns. Filial reverence and respect for parents and elders have always been a feature of Kazakh youth.

Motherhood is regarded by the people as a high value as a natural need to continue the human race. All people deservedly glorify woman to create a cult of the mother Typically, the Kazakhs say: "three times bring your mother to Mecca - you will never pay with the mother's duty".

Important role of the adults is constantly denoted in kazakh family.

Priority task for multinational people in Kazakhstan is to ensure equality of nations regarding historical justice and national traditions. This means that the preference is given to the national factor. Representatives of diasporas in Kazakhstan are also vested with rights as the citizens of ou country.

\section{Ethno-psychological aspects of Modern Education}

One of the consequences of globalization in the society is the loss of cultural identity which brings the crisis of people. It reduces the role of national culture, traditions and wealth of the mother-tongue. All this led to the changes of people's national psychology and their national identity. Thus, the crisis of national and cultural identity is considered as one of the most striking phenomena of our time.

However, self-identification process continuously occurs in market relations. Traditionalistic values amplified that have been somewhat different direction. Occurs rethinking and adapting to the new realities.

During this period, the transformation of consciousness leads to deformation of the national values of the Kazakh people. The impact of globalization significantly alters its psychology. All this leads to the spread of negative phenomena in the country: prostitution, drug abuse, increasing the number of single mothers among the Kazakhs. Along with this right in our society get their dissemination of such facts now as: changing its name to western-style, the appearance of Kazakh women in the military, in trade; the emergence of Kazakh homeless people, etc. Similar features of social life, is not typical to the mentality of Kazakhs, are found in domestic, personal sphere.

Thus, changes in the national consciousness of the Kazakh people is evident. In terms of market relevance is the issue of the influence of social environment on personality development. There are new challenges appears before a person that need to comprehend and to take concrete measures to resolve them. There are questions among them of formation of personality traits.

Global change in the lives of modern Kazakhstan leads us to the need to address the formation of ethnic identity. There are problems that must be solved by society as soon as possible.
From the former totalitarian system, we went to "inherited" the problem of "marginal personality", which is characterized by loss of national values, poor language and culture; mankurtizm, which is a manifestation of ignorance of their native language. The situation can be changed only by Kazakh people themselves. Big role in it belongs to, first of all, the Kazakh intelligentsia.

Social factors significantly affected the national consciousness of people. Rethinking the previous values gives rise to new values, new traits. This awareness is not based on the concept of national culture, but on a conscious assessment of modern life. New values are generated in the process of interaction between different cultures.

Thus, based on prevailing in the country a new economic situation, we can distinguish certain types of individuals who have different levels of development of national consciousness (outcasts mankurt, "new Kazakh" Oralmans). Transformation of consciousness has occurred under the influence of social factors.

However, we argue that there were changes in selfconsciousness, but all strains of indigenous fractures, folds into society has not happened. Traditionally, the mentality of the Kazakh nation was different development of such essential features as the quality of intelligence, observation, sociability, honesty, friendliness, justice. These national traits have allowed people to adapt successfully to a market economy.

According to the results of our studies [4, p. 202], despite the transformation of consciousness, basic values of Kazakh identity remained. So, for all age groups (seniors, students and adults) are characterized by the priority values of family, health. Reported increases in the values of active life, communication and security in the country.

Thus, despite significant shifts in the minds of the people, the modern Kazakh mentality once again turned to the traditional, historical roots. Evolution of consciousness as a whole has maintained a dominant ethnic and cultural core. It is not focused entirely on individualistic, rationalistic way of life. In addition, it should be noted that the essence has not changed people's mind about such moral categories as people, kindness, honor, duty.

The history of human civilization shows that the destruction of national traditions and values of the nation is completed both by loss and a general disaster as a reaction to the self-defense. Previous objectives had been lost during the Soviet period. The symbols which were unfamiliar to the people had replaced them. Ethnoses were imposed by unusual stereotypes. But as you know, the mechanical displacement of other national representations in our culture is fraught with the unpredictable consequences. The denial of national interests of nations is not taken into account in such a way.

However, the globalization of society has come to move from the ethnic confrontation to ethnic and cultural tolerance. Kazakh nation should build a tolerance, compassion and empathy to the foreign language individuals. This requires a special spiritual tolerance which assumes both the conservation of their convictions and the ability to tolerate the views and beliefs of other ethnic cultures.

President N.A. Nazarbayev underlines the tolerance as a special feature of the national character of the Kazakh people: "I would like to emphasize the tolerance and patience of people, their hospitality and friendliness in Kazakhstan. They endure the hardships of transition with the understanding and patience. These qualities are a 
serious pledge of our success and a consolidation of society "[5, p.103].

Stable educational strategy is necessary in making positive tolerant relations in our contemporary society. Forming a national model requires justification of educational institutions, implementing a scientific approach in defining the methodological frameworks and principles of their functioning. Specified conditions for effective implementation of the educational system in our country must responds to the basic requirements of the world educational space.

Except universal values an educational content makes up national values. Therefore, one of the tendencies of educational strategy should contribute to the solution of national interests. This means the development of national consciousness, harmonization of interethnic relations, the formation of Kazakhstani patriotism, spiritual rebirth of the people.

Years of independence have created the system of values that led to the emergence of a national ideology. Values are expressed in a feeling of patriotism, which performs an integrative function, contributing to unite all citizens of the multinational country. Traditionally, patriotism is regarded as a moral and political principle, the social sense, the content of which is love for the motherland. This patriotism is measured by how a person serves his fatherland and the people.

One of the tendencies of this work is to educate youth on the glorious traditions of Kazakh people. Educational process is a main way in deciding the given problem. A special role belongs to the humanities.

Under the guidance of prof. K. Zharikbaeva Republican Center of ethnopedagogics and ethnic psychology has successfully functioned in Kazakhstan. It implements a great co-ordinating role in the promotion and development of ethno-psychological and etnopedagogical knowledge in our country, promotes in preparing and stirring up scientific activities of young people.

\section{Conclusion}

The issues of ethnic and cultural education is the general part of education in the present day. In terms of Kazakhstan's multiethnic society the realization of this complex task is joined with the necessity of cultural dominants as the stem of national educational system. involves the need for cultural dominance as the core of the national education system. In this regard, the concept of ethno-cultural education had been developed in our country.

The strategy of ethnic and cultural education is aimed at the realization of ethno-cultural identity of the people, based on knowledge of their history and culture through the relevant ethno-cultural sphere. On the other hand, the state integration of efforts of all the nations living in this country is important. Most effectively it is achieved through the system of education.

The profound changes in the mentality of people is typical for the modern Kazakh society. Nowadays, the main emphasis is on education and development of personal qualities. It is getting quite obvious that the key to our future success will be the mobilization and concentration of intellectual resources.

\section{REFERENCES}

1. Nazarbayev N.A. Performance in a live TV program "Khabar", "Kazakhstan" and "Astana and the Kazakh Radio / / Kazakhstan Pravda, 14 November 2009.
2. Nysanbaev A.N. Globalization and Sustainable Development of Kazakhstan. - Almaty: Kazakhstan, 2002 - $264 \mathrm{sec}$.

3. Mardanov K. The transition to market: the ethnopsychological analysis of the path / / ethnopsychology and ethnopedagogy: Mater. Intl. Scientific teor.konfer. - Almaty: RIC, 1995 .- S.211-213.

4. Kukubayeva A.H. Phenomenology, structure, evolvement features of national self - consciousness (by the example of Kazakh ethnos). Almaty, 2009. $290 \mathrm{p}$.

5. Nazarbayev N.A. In the stream of history .- Almaty: Bilim, 1999.-296 p. 